\title{
Comparing vowel hiatus resolution in ciNsenga and chiShona: An Optimality Theory analysis: A reply to Galen Sibanda
}

\author{
Maxwell Kadenge \\ Linguistics Department, University of the Witwatersrand \\ E-mail: maxwell.kadenge@wits.ac.za

\begin{abstract}
Silvester Ron Simango
English Language and Linguistics Department, Rhodes University

E-mail: r.simango@ru.ac.za
\end{abstract}

In our article (Kadenge and Simango 2014), we set out to present an Optimality Theory (henceforth OT) analysis of intralinguistic and interlinguistic variation of vowel hiatus resolution in ciNsenga and chiShona. We note the variation between ciNsenga and chiShona with respect to how vowel hiatus is resolved in the verbal domain - specifically when the verb stem is V-initial: ciNsenga tolerates hiatus in those contexts whereas chiShona repairs the hiatus through the insertion of a glide (spreading). We account for these facts by proposing that ALIGN (ROOT $_{\mathrm{VERB}}, \mathrm{L}, \sigma, \mathrm{L}$ ) outranks both ONSET and ALIGNL-PSTEM in ciNsenga whereas in chiShona ONSET and ALIGNL-PSTEM outrank ALIGN (ROOT ${ }_{\mathrm{VERB}}, \mathrm{L}, \sigma, \mathrm{L}$ ). We argue that it is the difference in the ranking of these constraints that gives rise to this interlinguistic variation.

Galen Sibanda's (hereafter GS) summary, in the main, captures the essence of our article. However, there are a number of observations made by GS that we wish to comment on. Firstly, there is the suggestion that the article could have drawn on solutions from other branches of linguistics such as phonetics, morphology and diachronic findings. We wish to underscore the fact that one of the goals of phonological theory is to account for variation that normally manifests itself via allomorphy, which belongs to morphology. In fact, a closer reading of our article reveals that we have not departed from the long established view that one cannot insightfully account for Bantu phonology without considering facts from morphology and/or morphosyntax because phonological alternations or processes in Bantu are in many respects morphologically and syntactically conditioned.

We demonstrate in the article that different morphosyntactic domains trigger different repair strategies (see inter alia Myers 1987, Mudzingwa 2010, Mudzingwa and Kadenge 2011, Simango and Kadenge 2014, Downing and Kadenge 2015 for related discussion). For example, we show that hiatus in nouns and within the inflectional stem of the verb is resolved differently from hiatus across Prosodic Stem boundaries. Clearly, our article draws from findings in morphology and morphosyntax. We admit that we do not draw from findings in phonetics in 
this article; however, it remains an open question as to whether (and to what extent) phonology should draw from phonetics, which in itself is the implementation of phonological rules.

GS also raises an important question regarding the extent to which phonological theory (specifically OT) can account for diachronic change. While acknowledging that this OT account elegantly captures the typological variation between ciNsenga and chiShona, GS suggests that the proposed analysis only captures synchronic facts, but is silent on diachronic facts. We agree with GS that diachronic findings are crucial in phonological analyses. In section 5, we take cognisance of earlier proposals by Roberts-Kohno (1995) which suggest, on the basis of diachronic facts, that $\mathrm{V}$-initial verbs have undergone consonant loss and contain, instead, an empty $\mathrm{C}$ node which blocks hiatus resolution across prosodic stems, especially across the macro-stem boundary. We agree with this to the extent that it acknowledges that these verbs (in our critical data) were consonant-initial and that the consonants were lost at some point in the history of these languages.

The presence of this empty $\mathrm{C}$ would account for the ciNsenga facts where hiatus is tolerated across stem boundaries but would not account for chiShona data where the consonant, in the form of a glide, is overt. Note also that positing an empty $\mathrm{C}$ may not be universal across Bantu. In Zezuru, for example (see Fortune 1984: 10, Mudzingwa 2014: 66), it is generally accepted that the underlying representations of verbs like /en $\mathrm{d}-\mathrm{a} /$ ("go") and /on-a/ ("see") do not have a consonant in stem-initial position. The consonant only surfaces when the stem is preceded by other prefixes, suggesting that the consonants are epenthesised to resolve vocalic hiatus.

This point leads us to another of GS's questions: whether when dealing with allomorphs it is always best to choose one and to prefer epenthesis rather than elision. Note that in our article we emphasise the point that elision is the least preferred repair strategy because it results in the loss of all the features of a segment. Further, we point out that in the context of V-initial verbs consonant deletion would be dispreferred because it creates marked structures - namely onsetless syllables or vowel hiatus. Therefore, we believe that Shona inserts the glides (consonants) to provide syllable onsets to a marked structure and thus prevent vowel hiatus.

Thirdly, looking at the grammar in totality, epenthesis is always a preferred option to deletion. A clear example comes from how marked structures like complex onsets and codas are repaired in loanwords in chiShona and many other Bantu languages that have the CV syllable structure. In this case, vowel epenthesis is used instead of deletion (e.g. 'school' or 'train'- which have CCVC structure - are realised, respectively, as chikoro and tireni- which are CV.CV.CV).

To return to GS's original question on the extent to which phonological theory (specifically OT) can account for diachronic findings, we note that the question addresses an important issue that was beyond the scope of our article. It should be pointed out though that our use of OT to account for synchronic facts does not preclude the theory from being used as a useful tool to account for diachronic facts. In fact, the notion of constraint re-ranking underlying analysis of data in our article insightfully accounts for the linguistic variation that is rooted in diachrony.

\section{References}

Downing, L.J. and M. Kadenge. 2015. Prosodic stems in Zezuru Shona. Southern African Linguistics and Applied Language Studies 33(3): 291-305. 
Fortune, G. 1984. Shona grammatical constructions (Volume 2). Harare: Mercury Press.

Kadenge, M. and S.R. Simango. 2014. Comparing hiatus resolution in ciNsenga and chiShona: An Optimality Theory analysis. Stellenbosch Papers in Linguistics Plus 44: 105-127.

Mudzingwa, C. 2010. Shona Morphophonemics: Repair Strategies in Karanga and Zezuru. Unpublished $\mathrm{PhD}$ dissertation, The University of British Columbia.

Mudzingwa, C. 2014. Initial onsetless syllables in Karanga and Zezuru: A comparative analysis. Language Matters 45(1): 63-90.

Mudzingwa, C. and M. Kadenge. 2011. Comparing hiatus resolution in Karanga and Nambya: An Optimality Theory account. Nordic Journal of African Studies 20(3): 203-240.

Myers, S. 1987. Tone and the Structure of Words in Shona. Unpublished PhD dissertation, University of Massachusetts.

Roberts-Kohno, R. 1995. Vowel coalescence and hiatus in Kikamba. In A. Akinlabi. (Ed.) Theoretical approaches to African linguistics. New Jersey: Africa World Press. pp. 313-328.

Simango, S.R. and M. Kadenge. 2014. Vowel hiatus resolution in ciNsenga: An Optimality Theory analysis. Southern African Linguistics and Applied Language Studies 32(1): 79-96. 